\title{
EFEITO PAIDÉIA E O CAMPO DA SAÚDE: REFLEXÕES SOBRE A RELAÇÃO ENTRE O SUJEITO E O MUNDO DA VIDA
}

THE PAIDEIA EFFECT AND THE HEALTH FIELD:THOUGHTS ON THE RELATION BETWEEN SUBJECT AND LIFE-WORLD

Gastão Wagner de Souza Campos ${ }^{1}$

Resumo Este ensaio reflete sobre o modo como o método Paidéia lida com a relação entre a constituição de sujeitos e o mundo da vida. Apresenta alguns núcleos temáticos utilizados para analisar essa relação em situações concretas. Discute critérios para avaliar a noção de desenvolvimento político ou institucional. Comenta implicações da adoção desta metodologia no campo da saúde, especificamente para a prática da clínica ou da saúde pública.

Palavras-chave educação em saúde; gestão em saúde; política social.
Abstract This essay reflects on how the Paideia method handles the relation between the development of subjects and the life-world, presenting a few concepts used in its analysis in actual situations. The essay also discusses criteria for evaluating political or institutional development and comments on the implications of the adoption of this method on the health field - especially on clinical practice and public health.

Keywords education in health; health management; social policy. 


\section{O método Paidéia e a ação do sujeito no mundo da vida}

Os sistemas políticos se articulam em três instâncias básicas: primeiro, o contrato social de fundação e refundação da sociedade, isto é, toda uma rede de leis e de valores que compõem as instituições em uma dada sociedade; segundo, o governo e outros dirigentes que realizam a 'gestão' da rede de organizações que constituem a polis contemporânea, no caso, o Estado, empresas públicas e privadas e outras organizações religiosas ou comunitárias; terceiro, os sujeitos que vivem segundo essas leis e que se utilizam ou trabalham nessas organizações, ou seja, indivíduos e coletivos organizados que formam movimentos sociais, a opinião pública e grupos de interesse.

O método Paidéia busca o aperfeiçoamento de pessoas e instituições. Opera, portanto, diretamente sobre essa terceira instância da polis, isto é, procura realizar um trabalho sistemático junto aos próprios sujeitos, ampliando sua capacidade de atuar sobre o mundo que os cerca, particularmente sobre as instituições e organizações.

O método objetiva aumentar a capacidade de compreensão e de intervenção das pessoas sobre o mundo e sobre si mesmas, contribuindo para instituir processos de construção de sociedades com grau crescente de democracia e de bem-estar social.

Essa educação para a vida teria como escola a própria vida, mediante a construção de modalidades de co-gestão, que permitam aos sujeitos participarem do comando de processos de trabalho, de educação, de intervenção comunitária e, até mesmo, do cuidado de sua própria saúde. A gestão compartilhada da clínica ou da saúde pública pode se constituir também em um espaço onde se produza esse efeito Paidéia.

A Paidéia é, portanto, uma metodologia para a educação de pessoas objetivando a ampliação de sua capacidade de analisar e de intervir sobre o mundo. Não se trata de uma técnica neutra; o método sugerido apóia-se em alguns valores e critérios para balizar a política e a gestão. Não exige espaços terapêuticos ou pedagógicos especiais, como consultórios ou escolas, ainda que possa ser implementado também nesses lugares. O método Paidéia, para ser realizado, depende da constituição de espaços de co-gestão (co-gestão definida como compartilhamento de poder) e tem a pretensão de ser empregado no trabalho, na gestão de organizações, projetos ou movimentos sociais.

Ainda que seja auto-aplicável, dependendo da apropriação por um coletivo de seus conceitos fundamentais, o método ressalta a importância de ofertas externas para apoiar a mudança de pessoas ou grupos. Trata-se de uma metodologia que busca construir condições favoráveis para a reflexão sobre a atuação dos sujeitos no mundo, procurando sempre meios para que essa reflexão rebata sobre a imagem que os sujeitos têm de si mesmos. Busca 
o sentido forte do termo reflexividade: o pensamento se voltar sobre si a partir das evidências colhidas no mundo.

O conceito clássico de Paidéia já indicava essa possibilidade, ou seja, pressupunha a existência de um potencial de desenvolvimento em seres e sociedades humanas que adotassem princípios e procedimentos de uma educação integral dos sujeitos (Jaeger, 1986). Cidadania (direitos), democracia participativa (Ágora) e Paidéia constituíam a tríade imaginada pelos atenienses, durante o período clássico, capaz de garantir-lhes o bem-estar. $\mathrm{O}$ efeito Paidéia adviria de um trabalho interno, imanente às pessoas. A cidadania e a democracia contemplariam os elementos transcendentes a cada indivíduo, os quais constituiriam um ambiente favorável ao desenvolvimento integral das pessoas. Naquela época, a sociedade ateniense, em alguma medida, ao pensar um projeto de desenvolvimento, conseguia escapar da falácia de optar ou pelo indivíduo ou pelo coletivo; ou ainda, de escolher entre determinação estrutural e determinação da vontade humana, na explicação do destino e da história. A democracia ateniense, em tese, tentou apoiar-se nessas dimensões polares e durou enquanto foi possível (Stone, 2005).

O método Paidéia (Campos, 2000) procura meios para integrar essas dimensões polares da realidade: o mundo da vida e os sujeitos que intervêm sobre ele, ao mesmo tempo em que sofrem suas conseqüências. Para isto, sugere uma metodologia de análise com ênfase na interpretação da ação prática dos sujeitos no mundo. Com esse propósito, opera com alguns núcleos temáticos, uns referentes ao mundo, outros ao sujeito.

Os núcleos temáticos referentes ao mundo guardam uma relação com os sujeitos que fazem política, trabalham e vivem nesse mundo. E vice-versa. Assim, a finalidade da ação humana é um dos núcleos temáticos centrais a serem analisados pelos sujeitos da ação. Com que objetivos se elabora dada política de saúde, ou se faz gestão de serviços públicos, ou se trabalha com pessoas portadoras de risco ou de enfermidades?

Um segundo núcleo temático se refere aos meios utilizados pelos sujeitos para conhecer e intervir em um dado contexto. Qual o modo utilizado pelos sujeitos para realizar alguma tarefa ou implementar algum projeto? No fundo, é uma pergunta sobre a capacidade de análise e de intervenção: com que meios e métodos atuam a direção de um hospital público, uma equipe ou uma comunidade?

Um terceiro seria o objeto dos quais os sujeitos se encarregam: estariam assumindo responsabilidade sobre que elementos de uma dada situação? Ao realizar um estudo ou uma intervenção, as pessoas recortam pedaços da realidade, e esses fragmentos revelam o compromisso desses sujeitos. O quarto núcleo temático relativo ao mundo da vida é a análise do resultado das intervenções humanas: que produto tal organização, movimento ou projeto estariam produzindo? 
Conforme se observa, estes quatro núcleos temáticos constituem uma reutilização das categorias sugeridas por Marx para análise do processo de trabalho em O capital (Marx, 1985).

Por sua vez, os núcleos temáticos relativos ao sujeito dizem respeito a sua existência no mundo da vida. Um núcleo temático central ao método é o objeto de investimento: que afeto estariam os sujeitos da ação depositando no objeto ou no projeto sobre o qual agem, fazem política, gestão ou trabalham? Um segundo, qual capacidade têm estes sujeitos da ação de estabelecer pontes com o interesse de outros sujeitos, mediante a constituição de compromissos ou contratos? Um terceiro núcleo temático referente aos sujeitos é a análise da rede de poderes envolvidos em cada situação ou contexto: que conflitos, que institucionalidade, de que modo se exerce o controle social entre os sujeitos envolvidos em um hospital público ou espaço comunitário? Outro seria referente aos recursos de saberes ou de conhecimento, bem como dos valores de que os sujeitos envolvidos na ação têm disponibilidade, ou seja, uma análise dos referenciais culturais e tecnológicos de que se valem os sujeitos em um contexto concreto.

Quadro 1

Núcleos temáticos para análise Paidéia

Relativos ao mundo $\quad$ Finalidade/objetivo da ação humana

Resultado/ produto da ação humana

Meios de intervenção sobre o mundo

Objeto do qual se encarrega

Relativos ao sujeito

Objeto de investimento

Capacidade de estabelecer contratos e compromissos com outros

Análise da rede de poder em cada situação

Mecanismos de controle social

Referência cultural e ética

Realizar o percurso analítico acima sugerido não é uma tarefa simples. Ao contrário, depende de apoio externo e do estabelecimento de uma série de condições objetivas, entre elas a possibilidade de se organizarem espaços protegidos para a reflexão - rodas; depende ainda da substituição da violência como método para resolver conflitos, por processos de negociação entre interesses e perspectivas distintas. $\mathrm{O}$ método Paidéia se propõe a contribuir para a democratização das instituições, mas, paradoxalmente, depende bastante da instituição de espaços democráticos. 


\section{Critérios para análise segundo o método Paidéia}

O método Paidéia opera com a noção de que as mudanças são inevitáveis. Isto porque se filia à concepção de devir, decorrente da perenidade de tudo e de todos. Reconhece que as mudanças sociais resultam da interação de uma multiplicidade de fatores, externos e internos aos sujeitos. Uma espécie de dialética multifatorial, em que não haveria apenas tese e antítese seguidas de uma inevitável e previsível síntese, porém o cruzamento da influência de múltiplos fatores, que, ao interagirem, modificam não somente o resultado desses processos, mas também os próprios fatores envolvidos nessa mistura dialética que é a vida.

Pois bem, o método Paidéia é um recurso para colocar um pouco de intencionalidade nesse caldeirão de mudanças contínuas.

Quais seriam as finalidades em nome das quais se justificaria essa busca de intencionalidade por parte dos sujeitos? Para uma concepção teleológica, em geral, as finalidades costumam ser os principais critérios utilizados para avaliar um acontecimento.

Já para a corrente pragmática, à qual se filiam os pensamentos sistêmico e cognitivo tão em voga no século XXI, os resultados seriam os principais critérios para validar uma concepção ou uma metodologia de intervenção (Nicola, 2005). Quais seriam os resultados em nome dos quais se justificaria a busca de intencionalidade na política, na gestão e no trabalho?

Com que critérios, então, julgar se uma intervenção busca o tal aperfeiçoamento ou desenvolvimento das pessoas e instituições? O que seria desenvolvimento ou aperfeiçoamento de pessoas e de instituições? O que seria desenvolvimento político ou social?

O conceito de desenvolvimento é moderno. Com o Iluminismo, consolidou-se um forte sentimento de que o progresso social seria possível, ou como um processo cumulativo de pequenas mudanças - caracterizando uma perspectiva denominada de reformismo -, ou como rupturas abruptas de estruturas que emperrassem o referido progresso - em um modo revolucionário (Bobbio, 2000). De qualquer modo, consolidou-se a idéia de que haveria possibilidade de aperfeiçoamento social, de evolução do mais simples ao mais complexo, do injusto ao justo, da ignorância à sabedoria e do pior para o melhor.

Vários pensadores considerados pós-modernos negam essa trajetória e recusam a noção de progresso, retornando, em distintas variações, ao conceito de eterno retorno elaborado pelo filósofo Friedrich Nietzsche e, em conseqüência, a uma reafirmação da existência de um grau importante de circularidade na história (Harvey, 1993; Jameson, 1996).

Toda uma corrente de pensadores gregos, Heráclito entre eles, pensavam a vida como um movimento contínuo, em um permanente deslocar-se, 
chegando a forjar o conceito de "devir" (Schüller, 2001). Ao contrário do pensamento religioso oriental, que também descrevia a vida em fluxos, esses filósofos gregos anteviam a possibilidade de o ser humano interferir nesse processo. O hinduísmo ou o taoísmo atribuíam um poder imenso ao destino, relegando a um papel secundário na história a iniciativa humana (Russel, 1972). Todavia, não aparece em Heráclito uma ligação orgânica entre esse perpétuo movimento de mudança e a idéia de que esse fluxo conduziria a uma evolução contínua, ou a um aperfeiçoamento contínuo das instituições ou das relações sociais. Essa noção de progresso, de fato, aparece muito forte entre os iluministas. Entre os franceses enciclopedistas e em Kant e Hegel, particularmente, havendo este último filósofo elaborado uma síntese entre a concepção dialética de devir de Heráclito e a certeza iluminista de que, com o avanço do conhecimento, haveria um desenvolvimento da sociedade em espiral, com idas e retornos, mas, sempre, em sentido de um conhecimento absoluto, de um Estado perfeito e do fim da história (Kojève, 2002). O comunismo antevisto como paraíso terrestre é um desdobramento dessa concepção. Quando todas as contradições econômicas fossem eliminadas, os seres humanos viveriam em harmonia, organizados em uma sociedade que garantiria para cada cidadão, graças ao desenvolvimento dos meios de produção e ao aperfeiçoamento da máquina política, bens e serviços na exata medida de suas necessidades.

Apesar de ser considerado um dos fundadores da modernidade, Freud identificava uma tendência à repetição no comportamento individual dos seres humanos, opondo-se a esse otimismo que supunha o desenvolvimento linear ou em espiral ascendente da vida em sociedade. Esta perspectiva aparece tanto quando ele reconhecia a presença de uma dificuldade, inerente à natureza humana, de convivência social, como quando analisava a estruturação da personalidade individual. Haveria um mal-estar inevitável produzido pelas renúncias a que o viver em sociedade obrigava. As leis, as regras e os costumes imporiam limites ao desejo e a impulsos agressivos individuais; sem eles, a convivência caminharia rapidamente para a barbárie e para a mútua destruição. No entanto, estas imposições provocariam mal-estar, sintomas e mesmo doenças entre as pessoas (Freud, 1976, p. 327-245). Este conflito impediria tanto uma evolução linear da sociedade quanto o alcance, algum dia, de uma organização social tão harmônica que eliminasse esse padrão estrutural de conflito. Essa contradição funcionaria como um dilema que se recolocaria sempre em qualquer modalidade de organização social.

Ao construir o conceito de "transferência", um dos pilares de sustentação da teoria e da prática psicanalítica, ele observou que seus pacientes tendiam a relacionar-se com ele reproduzindo o modo como haviam se relacionado com autoridades familiares em sua primeira infância. Eles fariam uma transferência 
para o psicanalista de conflitos e de afetos experimentados no início de sua vida e, muitos deles, relegados ao esquecimento profundo (Freud, 1969, p. 207-222). Deleuze e Guattari (1976) criticaram essa concepção baseada na compulsão à repetição, analisando que cada tentativa de repetição de uma situação passada fatalmente seria diferente da anterior, tendo em vista a diferença entre os contextos e entre as pessoas envolvidas. De qualquer modo, haveria que se reconhecer que, de fato, há uma tendência nas pessoas a pensarem e atuarem usando referências do passado. Se uma pessoa aprendeu a lidar com a autoridade paterna de certa maneira, ao se deparar com outras autoridades, o professor, o médico ou o psicanalista, observa-se, de fato, uma tendência a repetir o estilo da relação anterior. Ou de enfrentamento aberto, ou de simulação e de fuga dos embates, etc. Ainda que seja importante reconhecer, como constataram Deleuze e Guattari, que as situações nunca serão equivalentes, não há como deixar de constatar que há situações análogas indutoras de identificações e movimentos repetitivos do pensamento e da ação dos sujeitos.

Trazendo essa discussão para o campo da política, da gestão e da vida cotidiana, poder-se-ia também reconhecer certa circularidade no funcionamento social, ainda que nunca haja um retorno ao mesmo de antes. Essa recorrência, essa tendência à repetição, resultaria da concentração de poder em determinados grupos ou classe sociais, da força das estruturas e das instituições interferindo na visão de mundo e no agir prático dos sujeitos. A lei, a ordenação das forças da natureza e das forças produtivas, a cultura, os valores, os costumes e os hábitos atuam conformando o modo como pensam e vivem os habitantes de certo tempo e de certo território. O ser humano tende a introjetar essas características externas, seja da cultura, da racionalidade econômica ou de valores predominantes em uma época, transformado-as em elementos singulares de sua própria subjetividade. Por isso parece tão difícil realizar mudanças na organização social.

De qualquer modo, conforme postulavam os dialéticos gregos e seus herdeiros iluministas, o ser humano não é inerte. Ele interage com essas estruturas e com a natureza. O mito de Prometeu, o homem que roubou o fogo dos deuses, permitindo a criação da indústria e ampliando os recursos necessários à proteção e ao conforto dos humanos, representa essa potência, essa possibilidade, esse imaginário (Brunel, 1998).

Caberia, no entanto, dirigir uma pergunta a esse mito: o que levaria alguns a agirem como Prometeu e outros não? Prometer e não prometer a si mesmo e aos outros a felicidade? Prometeu ludibriou ordens dos poderosos e, desrespeitando o estabelecido pela tradição, conseguiu o fogo para compartilhar com os semelhantes, um comportamento de desafio à autoridade, de habilidade calculada para lograr o seu intento e de solidariedade em repartir o bem adquirido com a humanidade. E ele fez tudo isso com a certeza 
de que haveria conseqüências, um preço a ser pago em virtude de sua preocupação com o coletivo e com a injustiça na distribuição de recursos importantes para a vida. Existiriam Prometeus na vida real?

Essa pergunta dirigida ao mito, no fundo, ressoa em outra interrogação: como podem os sujeitos interferir na história? Com que recursos? E em que sentido: egocêntrico ou com algum grau de solidariedade? Os critérios, voltemos a eles. Como julgar a política, a gestão, o trabalho e as ações cotidianas?

O método Paidéia busca apoiar e, ao mesmo tempo, avaliar o desenvolvimento de pessoas e de instituições segundo três critérios fundamentais:

1) Reconhecer que uma das finalidades principais da política, da gestão e do trabalho humano é a construção de bem-estar e justiça social.

Realçar a importância da defesa da vida como um critério de julgamento para as ações humanas. Introduzir com ênfase o tema da eficácia, cada vez mais deslocado pelo critério da eficiência. Na sociedade contemporânea, predomina a busca incessante por maior produtividade objetivando aumentar a capacidade competitiva dos agentes (Harvey, 1993) e não necessariamente os valores de uso produzidos. Usar o fator humano como analisador e balizador do governo, da economia e da política. Fundir o conceito de finalidade com o de resultado, finalismo e pragmatismo mesclados: que benefícios cada ação traz para a coletividade? Que setores serão beneficiados?

O método Paidéia propõe trazer para o centro da discussão a repercussão de cada ação sobre a vida humana. Assim, uma economia que andasse bem, mas com um povo que andasse mal, seria desaprovada por esse critério Paidéia, que seria a capacidade de produzir bem-estar e justiça social. Um hospital estatal ou privado deveria, em primeiro lugar, ser avaliado por sua capacidade de produzir saúde; em segundo, considerar-se-ia sua eficiência, isto é, a maior ou menor capacidade de utilizar meios com racionalidade e economia.

Observa-se, nos últimos tempos, uma degradação da política e da atividade econômica. O exercício da política tem colocado a luta pelo poder à frente do compromisso de governar a polis de maneira equânime e justa. Predomina um realismo político que considera ingênua qualquer postura que não traga para o centro do palco a conquista e manutenção do poder, tomadas como um fim em si mesmo. O pensamento estratégico teria essa base, o jogo pelo poder. Com isso, a proteção social, a distribuição de renda, a segurança pública, o modelo de gestão do campo da saúde ou da educação, tudo é submetido à racionalidade da luta pelo poder. O interesse particular de grupos ou de pessoas em concentrar poder tem predominado sobre o interesse coletivo de se ter governos com capacidade para assegurar o bem-estar.

O método Paidéia não preconiza, ou sequer imagina possível, a organização social sem a disputa pelo poder. Ao contrário, essa disputa é essencial 
à democracia. O problema tem sido o deslocamento de ênfase. O poder seria um meio para o bom governo da polis, não um fim em si mesmo. Ainda que, para alguns grupos ou pessoas - políticos profissionais -, participar do poder seja também um fim em si mesmo (afinal, como ironizava Henfil, "eles precisam sobreviver"), a sociedade, por outro lado, também precisa construir contra-poderes que limitem a agudeza dessas disputas. Desenvolver meios políticos - fora do circuito profissional da política - que obriguem os poderosos a cumprirem também com sua responsabilidade com os outros, no caso, com a maioria.

Essa diretriz indica um compromisso do método Paidéia com a eqüidade, ou seja, com a mudança e com a reforma de leis, estruturas e posturas pessoais que reforçam ou sustentam qualquer forma de injustiça.

2) A política, a gestão e o trabalho deveriam ser julgados também por sua capacidade de construir os maiores coeficientes possíveis de autonomia e de liberdade para as pessoas e instituições.

Isto implica em assegurar ao indivíduo e à coletividade a possibilidade de expressão dos desejos, interesses e valores particulares ou singulares com a máxima liberdade. Bem como criar espaços onde estas diferenças, além de virem à tona, possam ser objeto de compromissos e de contratos entre os atores sociais envolvidos.

Para o método, autonomia não significa independência ou descompromisso absolutos. Ao contrário, a ampliação da autonomia depende da capacidade do sujeito em reconhecer e lidar com a rede de dependência na qual estão todos inevitavelmente mergulhados.

Essa diretriz indica um compromisso do método com a democracia, ou seja, com a democratização da vida em sociedade e com uma ampla reforma dos modos de fazer política e de fazer gestão. Acena-se com a possibilidade de limitar o poder das autoridades - políticas, econômicas, disciplinares e outras - com contra-poderes oriundos da ampliação da capacidade de analisar e de intervir da maioria das pessoas.

3) Assegurar a resolução de conflitos e a elaboração de contratos entre interesses e valores diferentes sem o uso da violência, mas graças ao uso de instrumentos de convencimento e de negociação.

Talvez fosse mais realista afirmar: com o menor uso de violência possível, já que há formas e formas de convencimento, e uma delas, a pressão social, sempre inclui alguma forma de constrangimento contra poderosos relutantes em dividir riqueza e poder, mas também contra explorados constrangidos a desistir de lutar pela mudança. Para muitos, isto poderia ser considerado uma forma de violência; talvez?

De qualquer modo, essa diretriz enfatiza a necessidade de realizar um combate sistemático à violência e às situações e condições que facilitem ou possibilitem o uso da violência entre pessoas. 


\section{O campo da saúde e o método Paidéia}

O trabalho em saúde, seja clínico ou preventivo, objetiva alterar uma situação considerada inadequada; aposta em um devir, isto é, em um processo de mudança. Implica, portanto, na intervenção ativa de sujeitos que irão mobilizar recursos para alterar a situação negativa.

A medicina e a saúde pública tradicionais consideram as comunidades e grupos populacionais como objetos a serem controlados ou manipulados em função do saber clínico ou epidemiológico, ou seja, operam com um objeto reduzido: a doença em sua expressão individual ou populacional. Como se não houvesse pessoas envolvidas. O método Paidéia busca ampliar essa concepção do objeto de conhecimento e de intervenção do campo da saúde: toma as doenças e os problemas de saúde em sua expressão individual e coletiva, mas encarnados em pessoas concretas. O método Paidéia não descarta a importância da doença, mas incorpora também a noção de problemas de saúde (situações que aumentam o risco e a vulnerabilidade das pessoas), além de ressaltar que não existe doença, risco ou vulnerabilidade separada de pessoas concretas. Neste sentido, toma como objeto também a capacidade de intervenção das organizações e dos sujeitos sobre esses problemas.

O método sugere, portanto, uma ampliação do objeto da clínica e da saúde coletiva; não uma negação ou substituição radical do objeto tradicional dessas disciplinas, conforme alguns autores chegaram a recomendar. Ao criticar a medicina tradicional, alguns autores sugeriram o abandono do conceito de doença, que deveria ser substituído pelo de saúde. Para o método, o objeto é aquilo do que se encarrega para analisar e intervir; no caso, o objeto do qual se encarrega o setor saúde é o risco, a vulnerabilidade e a própria doença, encarnados em indivíduos e grupos concretos de pessoas.

Para o método Paidéia, a produção de saúde seria a finalidade ou o objetivo do trabalho, dos sistemas e das políticas da área sanitária. O objetivo ampliado das políticas e dos sistemas seria a produção de saúde, mediante intervenções para prevenir doenças, promover situações e ambientes saudáveis, bem como medidas clínicas para recuperar e reabilitar pessoas enfermas.

Além disso, o método incorpora, também como objetivo para a clínica e para a saúde coletiva, a busca permanente em ampliar o grau de autonomia dos sujeitos usuários dos serviços ofertados. E este é um efeito tipicamente Paidéia, a ampliação da autonomia de uma pessoa depende sempre da ampliação de sua capacidade de compreender e de agir sobre o mundo e sobre si mesma.

Para o método Paidéia o objetivo do trabalho em saúde seria, pois, a própria produção de saúde, ou seja, defender a vida, mediante políticas de proteção social, mas também mediante uma ampliação da compreensão e da capacidade de as pessoas agirem de modo comunicativo e solidário. Com este fim, é importante construir a capacidade de essas pessoas identificarem e 
trabalharem temas que sejam objetos de investimentos para elas mesmas, ou seja, que atendam parcelas de seu desejo e interesse e tenham significado e relevância para a sua própria vida e para os pedaços de mundo envolvidos nesse contexto.

Juntamente com esse propósito, é fundamental a construção de novas organizações e de uma nova sociabilidade que estimule e facilite a modificação das relações entre os governos, gestores, trabalhadores de saúde e destes com os usuários.

A medicina e a saúde pública tradicionais também operam com uma redução em relação aos meios de intervenção. Em saúde, há meios de intervenção voltados para o diagnóstico da situação individual ou coletiva e meios dirigidos ao momento da terapêutica ou da intervenção propriamente dita sobre o contexto considerado inadequado. No momento do diagnóstico, há uma redução quando se pratica uma objetivação positivista, tanto na análise epidemiológica (dados de mortalidade, morbidade, avaliação de risco), quanto na clínica (dados do exame físico ou evidências resultantes de exames complementares). O método Paidéia sugere uma síntese entre os saberes clínico e epidemiológico objetivos e a história do sujeito ou do grupo populacional, o que inclui analisar a capacidade de intervenção dessas pessoas sobre a produção de saúde.

Esta síntese entre evidências objetivas e uma narrativa subjetiva permitiria a composição de um texto mais próximo às características da situação indesejada e sobre como ela vem sendo produzida. Neste texto é utilizada informação epidemiológica, clínica e assistencial para descrever o problema. Para identificar fatores subjetivos, sociais e culturais envolvidos com a produção do problema sanitário, valer-se de representação dos sujeitos envolvidos, valorizando sua experiência e sua vivência. Os dados para composição desse texto a ser analisado e interpretado podem advir da observação empírica por parte da equipe; de sua capacidade de escuta do discurso dos usuários; do levantamento de conhecimentos acumulados sobre o problema; de protocolos, programas ou relatos de experiências; dados sobre recursos e situação sanitária.

A interpretação do texto é necessária para orientar a tomada de decisões e definição de tarefas, tanto para os profissionais quanto para os usuários ou rede de apoio. A interpretação depende da capacidade de se elaborar modelo explicativo para a produção do problema e de se construírem modos de interferir no problema de forma a atenuá-lo ou erradicá-lo. As diretrizes políticas e os valores vigentes em cada situação devem ser incorporados nesse diagnóstico.

No momento terapêutico ou da ação sobre a situação de risco, também se pratica uma redução de perspectiva na clínica e na saúde pública tradicionais. Em geral, opera-se com a vigilância epidemiológica e sanitária e com fármacos ou cirurgias na clínica. Para o método Paidéia, seria neces- 
sária uma ampliação: com certeza, realizar esses procedimentos quando necessários, mas, além disso, incorporar no projeto terapêutico ou de intervenção ações objetivando reorganizar a atenção à saúde e a estruturação social, bem como procedimentos para a ampliação do saber e da capacidade de cuidado das pessoas, famílias e comunidade.

Para que esta linha de trabalho seja possível, é fundamental adotar-se a gestão compartilhada do projeto terapêutico individual ou do projeto de saúde pública. A gestão compartilhada da clínica e da saúde coletiva altera a postura e o papel da equipe de saúde e dos serviços, que deveriam passar a funcionar como apoio. A construção de objetos de investimento, isto é, construir sentido e significado para o trabalho sanitário conjunto, é um dos caminhos para ampliação das possibilidades de intervenção da equipe de saúde. Até porque a constituição de objetos de investimento nunca ocorre por ação unilateral dos profissionais, depende sempre do concurso ativo dos usuários.

A gestão compartilhada da clínica e da saúde coletiva é um meio para a constituição de vontade de mudança, bem como de um bloco de sujeitos comprometidos, em distintos graus, com projeto terapêutico individual ou sanitário, conforme o caso em tela. O método procura identificar os sujeitos e organizações potencialmente implicadas com o projeto: usuários interessados, equipes profissionais, rede social de apoio, bem como grupos com interesses contrariados e possíveis opositores ao projeto.

A criação de rodas - espaços coletivos - entre sujeitos implicados com o projeto é um passo metodológico importante. Desta interação é que deveriam surgir os problemas prioritários a serem enfrentados: alguns ofertados pela equipe profissional e outros demandados pelos próprios usuários. As ofertas dos profissionais se baseiam no conhecimento clínico e epidemiológico, bem como nos núcleos temáticos acima descritos. A gestão compartilhada da clínica ou do projeto sanitário depende da construção de contrato entre profissionais, usuários e outras pessoas envolvidas com o problema ou com organizações da rede de apoio. É óbvio que os papéis e responsabilidades dos vários sujeitos envolvidos são distintos e devem ficar explicitados. Desta interpretação devem surgir tarefas para os distintos atores sociais: intervenções clínicas, epidemiológicas, pedagógicas, diretrizes para reorganizar atenção à saúde e para alterar ambiente ou organização social. A definição dos sujeitos responsáveis e dos implicados em cada tarefa depende de seus papéis profissionais e da implicação de cada um com a situação.

Para o funcionamento reflexivo é importante realizar-se, de modo sistemático, a análise da sustentabilidade e dos resultados dessas intervenções. Essa reflexão sobre a prática é um excelente instrumento para diminuir as resistências estruturais de cada sujeito, como também é importante para a 
redefinição do diagnóstico, da interpretação e da rede de tarefas anteriormente definidas.

Para encerrar este ensaio, valeria repetir: dificilmente haverá projeto compartilhado, alguma forma de co-gestão, sem a construção de objetos de investimento que motivem usuários, equipes e redes de apoio a saírem de si mesmos sem abandonar-se.

\section{Nota}

${ }^{1}$ Livre-Docente da Universidade Estadual de Campinas (Unicamp). Doutor em Saúde Coletiva pela Unicamp. <gastão@fcm.unicamp.br>

\section{Referências}

BOBBIO, Norberto. 2000. In: BOVERO, Michelangelo (org.). Teoria geral da politica: a filosofia política e a lição dos clássicos. Rio de Janeiro: Campus.

BRUNEL, Pierre (org.) 1998. Dicionário de Mitos Literários, 2a. ed. Rio de Janeiro, Editora UnB / José Olympio.

CAMPOS, Gastão Wagner S. 2000. Um método para análise e co-gestão de coletivos. São Paulo: Hucitec.

DELEUZE, Gilles; GATTARI, Félix. 1976. O anti-édipo: capitalismo e esquizofrenia. Rio de Janeiro: Imago.

FREUD, Sigmund. 1976. Por que a guerra (cartas entre Einstein e Freud) In: Edição standard brasileira das obras psicológicas completas de Sigmund Freud, vol. XXII. Rio de Janeiro: Imago.

FREUD, Sigmund. 1969. Observações sobre o amor transferencial (novas recomendações sobre a técnica da psicanálise). In: Edição standard brasileira das obras psicológicas completas de Sigmund Freud, vol. XII. Rio de Janeiro: Imago
HARVEY, David. 1993. Condição pós-moderna. São Paulo: Loyola.

JAMESON, Frederic. 1996. Pós-modernismo: a lógica cultural do capitalismo tardio. São Paulo: Ática.

JAEGER, Werner. 1986. Paidéia: a formação do homem grego. São Paulo: Martins Fontes.

KOJÈVE, Alexandre. 2002. Introdução à leitura de Hegel. Rio de Janeiro: Contraponto.

MARX, Karl. 1985. O capital: crítica da economia política. 2a ed. São Paulo: Nova Cultura.

NICOLA, Ubaldo. 2005. Antologia ilustrada de filosofia: das origens à Idade Moderna. São Paulo: Globo.

RUSSELL, Bertrand. 1972. A history of western philosophy. Nova York: Simon \& Schuster.

SCHÜLER, Donaldo. 2001. Heráclito e seu (dis)curso. Porto Alegre: L\&PM.

STONE, Isidor F. 2005. O julgamento de Sócrates. São Paulo: Companhia das Letras.

Recebido em 15/02/2006

Aprovado em 13/03/2006 